\title{
Organic thermal maturity as a proxy for frictional fault heating: Experimental constraints on methylphenanthrene kinetics at earthquake timescales
}

\author{
Rachel E. Sheppard ${ }^{\mathrm{a}}$, Pratigya J. Polissar ${ }^{\mathrm{b}, *}$, Heather M. Savage ${ }^{\mathrm{b}}$ \\ ${ }^{a}$ Department of Earth and Environmental Science, Columbia University, United States \\ ${ }^{\mathrm{b}}$ Lamont-Doherty Earth Observatory of Columbia University, 61 Route 9W, Palisades, NY 10964, United States
}

Received 5 September 2014; accepted in revised form 24 November 2014; Available online 8 December 2014

\begin{abstract}
Biomarker thermal maturity is widely used to study burial heating of sediments over millions of years. Heating over short timescales such as during earthquakes should also result in measurable increases in biomarker thermal maturity. However, the sensitivity of biomarker thermal maturity reactions to short, higher-temperature heating has not been established. We report on hydrous pyrolysis experiments that determine the kinetic parameters of methylphenanthrene maturation at timescales and temperatures relevant to earthquake heating. Samples of Woodford Shale were heated at temperatures up to $343{ }^{\circ} \mathrm{C}$ over 15-150 min. The thermal maturity of the samples as measured by the methylphenanthrene index-1 (MPI-1) increased with heating time and temperature. We find that MPI-1 increases with time and temperature consistent with a first-order kinetic model and Arrhenius temperature relationship. Over the timescales tested here, MPI-1 is strongly affected by maximum temperature and less sensitive to heating duration. Production of new phenanthrene isomers and expulsion of a liquid pyrolyzate also occurred. Differential expulsion of methylphenanthrene isomers affected the apparent maturity of the rock at lower temperatures and may need to be considered for organic-rich fault rocks. Our results demonstrate that the overall MPI-1 reaction extent in both the rock and pyrolyzate are a useful measure of thermal maturity and reflect temperature history during rapid heating.
\end{abstract}

(c) 2014 Elsevier Ltd. All rights reserved.

\section{INTRODUCTION}

The kinetics of organic thermal maturity reactions are a function of both time and temperature and occur over a wide range of conditions during earth processes. However, most studies of organic thermal maturity kinetics have focused on longer timescales applicable to burial heating of organic matter and generation of petroleum. There is increasing interest in using organic thermal maturity to study heating processes at much shorter timescales such

\footnotetext{
* Corresponding author. Tel.: +1 8453658400 .

E-mail address: polissar@Ideo.columbia.edu (P.J. Polissar).
}

as occurs during earthquakes, lightning strikes, bolide impacts, dike intrusions, and drill bit metamorphism (Raymond and Murchison, 1992; Daly et al., 1993; Simoneit et al., 1994; Farrimond et al., 1999; O’Hara, 2004; O'Hara et al., 2006; Bowden et al., 2008; Schimmelmann et al., 2009; Wenger et al., 2009; Parnell et al., 2010; Polissar et al., 2011; Sakaguchi et al., 2011; Fulton and Harris, 2012; Kitamura et al., 2012; Savage et al., 2014). Extrapolation of kinetics determined for slow, burial-heating rates to the short timescales of these processes is highly uncertain.

Here we determine the kinetics of thermal maturation of methylphenanthrene compounds at timescales and temperatures important for shear heating during earthquakes. 
The frictional work (the product of shear stress and fault slip) done during an earthquake is dissipated as heat, in some cases leading to temperature rise great enough to melt the fault materials $\left(>1000^{\circ} \mathrm{C}\right)$. However, frictional melt is not often detected along faults (Kirkpatrick et al., 2009; Kirkpatrick and Rowe, 2013), potentially due to extreme fault weakening during sliding brought on by various micromechanical processes (Di Toro et al., 2011). Because of a lack of other paleothermometers for faults zones, it is difficult to estimate temperature rise when frictional melt is absent.

Thermal maturity of organic molecules offers a possible alternative to determine temperature rise, and subsequently estimate shear strength and fault slip during an earthquake. Earthquake heating along a fault occurs during the earthquake event, $\sim 1$ to $10 \mathrm{~s}$ depending on the size of the event and slip velocity. However, heat dissipation occurs over longer timescales, and reaction of chemical compounds should continue as heat dissipates over minutes to hours. These timescales are much shorter than prior experiments on organic thermal maturity reactions. Here we focus on methylphenanthrenes because they appear to be common compounds in geologic faults hosted within sedimentary rocks at burial depths of $1-5 \mathrm{~km}$ (Polissar et al., 2011). To our knowledge, these are the first experiments on these compounds in this time/temperature range. We compare our results to previous estimations of methylphenanthrene maturation based on correlations during slow, burial heating of vitrinite. Finally, we discuss potential applications for the results to determine temperature rise on faults during earthquakes.

\section{BACKGROUND}

Heating of sediments systematically alters the chemical composition of organic material contained within the rock as thermally unstable compounds break down relative to more stable compounds, and rearrangements of molecules to more stable structures occur. This process of thermal maturation favors generation and preservation of molecules with low $\mathrm{H} / \mathrm{C}$ ratios, as the ultimate fate of heated organic matter is transformation to graphite and other highly stable, hydrogen-poor structures. Polycyclic aromatic hydrocarbons (PAHs) are an important class of petroleum molecules used to assess thermal maturity. These hydrogen-poor molecules contain conjugated aromatic rings that are the building blocks of graphite and are stable at high temperature.

\subsection{Methylphenanthrenes}

Methylphenanthrenes are methylated polycyclic aromatic hydrocarbons whose pattern of methylation changes with thermal maturity. Methylation at the 9 and $1(\alpha)$ positions increases steric strain in the molecule, causing those isomers to be less stable compared to the 3 and 2 $(\beta)$ positions (Fig. 1). Consequently, the $\alpha$ isomers 9- and 1-methylphenanthrene (9-MP and 1-MP) are less stable, breaking down at high temperatures, while the $\beta$ isomers 3- and 2-methylphenanthrene (3-MP and 2-MP) are more

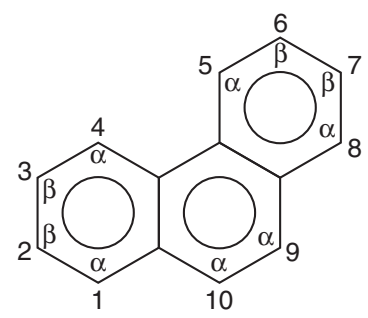

Fig. 1. Molecule structure of phenanthrene and numbering of $\alpha$ (less stable) and $\beta$ (more stable) methyl positions.

stable at high temperatures (Radke et al., 1982a; Szczerba and Rospondek, 2010). This varied stability at high temperatures forms the basis of the methylphenanthrene index MPI-1, the ratio of stable $\beta$-methylphenanthrenes to unstable $\alpha$-methylphenanthrenes used as a measure of thermal maturity.

Phenanthrene and methylphenanthrenes are created during thermal maturation of organic matter. They are not synthesized by any known organism, but rather formed by alteration of precursor molecules during heating. Methylphenanthrenes have been found in samples of very low thermal maturity $(0.4 \%$ vitrinite reflectance), suggesting they can be formed early in the maturation process (Szczerba and Rospondek, 2010). Once formed, alteration, destruction and expulsion of phenanthrenes can occur. Alteration includes interconversion of different methylphenanthrenes via isomerization (Szczerba and Rospondek, 2010). Alteration can also occur via transmethylation between phenanthrene and a methyl donor, affecting the relative abundances of phenanthrene and methylphenanthrenes during heating (Szczerba and Rospondek, 2010). Destruction occurs when the triaromatic ring nucleus that defines phenanthrenes is altered through addition or cracking reactions. Expulsion describes the migration of liquid hydrocarbons out of the primary source rock into surrounding sediments. Expulsion can alter both the overall concentration of molecules in the source rock and the relative distribution of molecules by differential expulsion. Migration of fluids through a rock can also leave traces of methylphenanthrenes and other small molecules. The distribution of phenanthrene molecules in a sample therefore reflects the prior heating history of the sample through the creation, alteration, destruction and expulsion of these molecules plus any fluids that may have migrated through the rock.

Previously, the maturation of methylphenanthrenes has only been evaluated at longer timescales (Radke et al., 1982a, 1982b, 2000; Radke, 1988; Armstroff et al., 2006) and the kinetic parameters describing methylphenanthrene maturation have not been determined. Existing estimates for methylphenanthrene maturation rates therefore rely upon an empirical relationship between methylphenanthrene maturity and vitrinite reflectance. The kinetics of vitrinite reflectance are reasonably constrained across laboratory and geologic heating rates (Burnham and Sweeney, 1989; Sweeney and Burnham, 1990). Therefore, vitrinite reflectance can be calculated for most possible 
time-temperature histories, and the corresponding methylphenanthrene maturity can then be determined from the empirical relationship. This relationship is determined from slowly heated basin sediments and then extrapolated to other settings. Accordingly, this calculation assumes that vitrinite reflectance and methylphenanthrene maturity evolve similarly across a wide range of heating rates and temperatures (Polissar et al., 2011). However, studies of sediments heated by igneous dike intrusions suggest that methylphenanthrenes mature more slowly than vitrinite during shorter, higher temperature heating events (Raymond and Murchison, 1992; Bishop and Abbott, 1995). These observations indicate that the correlation between methylphenanthrene maturity and vitrinite reflectance cannot be extrapolated from slow, burial heating rates to short, high temperature heating events such as during an earthquake. Here we experimentally observe the maturation of methylphenanthrene molecules at much shorter timescales to develop kinetic parameters applicable to rapid heating of geologic materials.

\section{METHODS}

\subsection{Samples}

Hydrous pyrolysis experiments were carried out on crushed Woodford Shale, an organic-rich, relatively thermally immature shale sampled in central Oklahoma, previously used in hydrous pyrolysis experiments (Lewan et al., 1979; Lewan, 1997). The Woodford Shale is appropriate for our laboratory heating experiments because it is a wellstudied benchmark. Experiments need not be run at very high temperature to study the kinetic reactions due to its low thermal maturity, and the high organic content allows heating and analysis of small samples.

Samples of the Woodford Shale were collected from the same outcrop previously described in Lewan (1997) (a road cut on the west side of Interstate 35 at $34.35131{ }^{\circ} \mathrm{N}$, $\left.97.14847^{\circ} \mathrm{W}\right)$. While we were unable to determine the exact bed collected by Lewan (1997), our samples come from sediments with an identical burial history to those used in their previous hydrous pyrolysis study.

The Woodford Shale is an organic-rich DevonianMississippian shale containing immature Type-II organic matter (Cardott and Lambert, 1985; Lewan, 1997; Romero and Philp, 2012). At our sampling locality, mean vitrinite reflectance measurements $\left(R_{m} \quad 0.41 \pm 0.05 \%\right.$, Lewan, 1997; Romero and Philp, 2012) place the shale into the pre-oil generation stage. Preliminary comparison of indurated chert-rich and friable chert-poor samples from the outcrop demonstrated identical molecular distributions ( $n$-alkane, sterane, hopane, methylnaphthalenes, methylphenanthrenes) but considerably higher concentrations in the chert-poor sample. We selected the higher-concentration, chert-poor material for our study due to the limited volume of the pyrolysis reactor. A hand sample of the shale was scrubbed with de-ionized water, rinsed with dichloromethane to remove any surface contamination and crushed with a solvent-cleaned chisel and hammer to $\sim 2$-mm-size pieces. The sample was then further crushed in a cleaned mortar and pestle to yield a distribution of grain sizes. The grains were sieved through 710 and $250 \mu \mathrm{m}$ screens and the 250 $710 \mu \mathrm{m}$ fraction selected as the maximum size that could easily be loaded into the narrow reactor. This restricted grain size range was used to ensure no appreciable difference in the time it took heat to diffuse through each grain.

\subsection{Rapid heating apparatus}

The rapid heating apparatus consists of a narrow stainless steel reactor ( $15 \mathrm{ml}, 7 \mathrm{~mm}$ diameter) (Fig. 2). Fittings at the base allow a $1 / 8$ " J-type thermocouple to feed into the center of the reactor. The top of the reactor connects to a pressure transducer and valves that allow the reactor to be evacuated, purged with helium gas and sealed during the experiments. The inner wall of the reactor was carburized by heating several organic-rich samples prior to running the experiments described here. Two resistive heaters (330 W Watlow Cable Heater, p/n 62H56A4X-886) are wound around the outside of the reactor. A second external $1 / 16$ " J-type thermocouple is affixed to the outside of the reactor, directly in contact with the outside metal wall. Temperature is controlled by an Omega proportionalintegral-derivative (PID) controller with feedback from the external thermocouple. The internal thermocouple measures temperatures within the rock sample during the

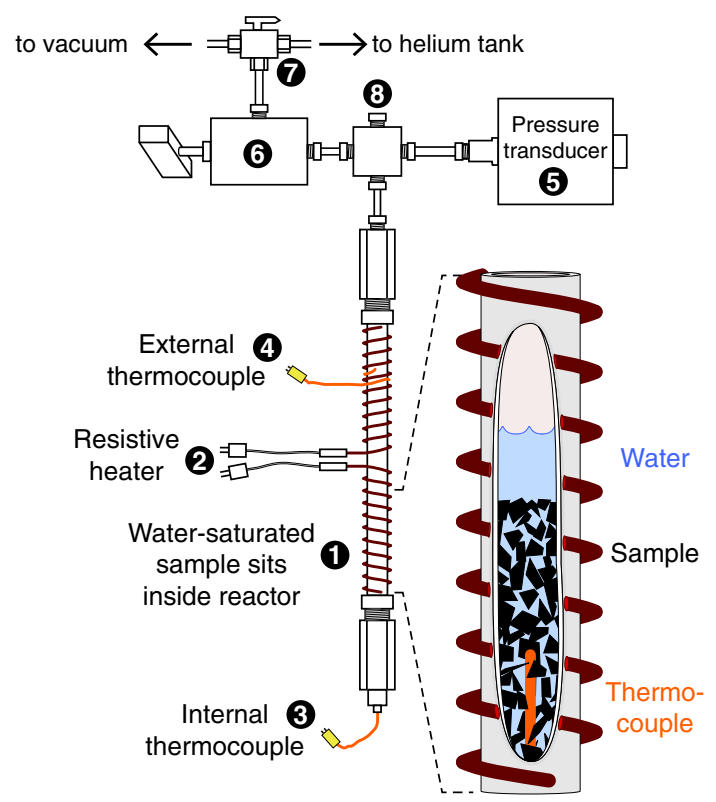

Fig. 2. Reactor used for rapid hydrous pyrolysis experiments. The reactor (1) is wrapped with two resistive heaters (2) and has an internal thermocouple (3) that measures the temperature during an experiment. An external thermocouple (4) provides feedback to a partial-integral differential (PID) controller that heats the reactor. A pressure transducer (5) monitors system pressure during an experiment and is attached to a four-way cross that is opened to release pressure after an experiment (8). A high-pressure valve (6) isolates the reactor and transducer during an experiment while a two-way Swagelok ${ }^{\circledR}$ valve (7) allows air to be pumped out of the reactor and the reactor to be charged with helium before an experiment. 
experiment. Glass-fiber insulation was wrapped around the entire length of the reactor. Pressure (from generation of steam and volatile gases) and internal and external temperature were recorded at $1 \mathrm{~Hz}$ throughout the experiment.

\subsection{Hydrous pyrolysis experiments}

To prepare an experiment, the reactor, already sealed at the bottom with the internal thermocouple attached, was filled with $3.45 \mathrm{ml}$ Optimum-grade ultra-purified water (organics-free) and then $6 \mathrm{~g}$ of Woodford Shale pieces $(250-710 \mu \mathrm{m})$. The shale was added slowly to the reactor after the water to ensure that the pieces distributed evenly through the water and did not form a plug within the reactor. The water volume was optimized to completely cover the rock sample at all times (Lewan, 1993) while not over-pressuring the reactor as the water expands at high temperature.

The reactor was attached to the support frame and a vacuum pump removed the air $(10 \mathrm{~s})$. The system was pressurized to $6.90 \mathrm{MPa}(1000 \mathrm{psi})$ with ultra-high-purity helium and leak checked with a helium detector. The pressure was then released and the system pressurized with $1.38 \mathrm{MPa}$ (200 psi) helium to provide an inert atmosphere for the experiments.

At the end of the experiment the reactor was rapidly cooled by removing the insulation, spraying water onto the outer surface, and blowing air with a fan. Once cool, the top fitting on the reactor was removed and the reactor detached from the frame. The reaction products were poured into a jar, the bottom fitting removed and residual oil and rock rinsed into the jar with organics-free de-ionized water.

Between experiments, the connectors, reactor, and internal thermocouple were cleaned with high pressure boiling water, detergent, deionized water, methanol, and dichloromethane. A soft brush was used on the connectors, but no abrasive materials were used on the inside of the reactor to avoid destroying the carburized layer.

\subsection{Sample extraction}

The reaction products (water and rock) from the hydrous pyrolysis experiments were separated into liquid (water plus expelled bitumen or pyrolyzate) and solid (shale) fractions by filtering through a glass fiber filter (Whatman $\mathrm{GF} / \mathrm{F}$ pre-combusted at $450{ }^{\circ} \mathrm{C}$ for $8 \mathrm{~h}$ ). The solids on the filter were rinsed with organics-free de-ionized water, methanol and dichloromethane (all Optima grade, Fisher) to ensure that no pyrolyzate remained on the shale pieces, and then allowed to dry overnight at room temperature.

The pyrolyzate was recovered from the aqueous filtrate by liquid-liquid extraction in a glass separatory funnel using three $20 \mathrm{ml}$ aliquots of dichloromethane. The dichloromethane pyrolyzate extract was evaporated to $\sim 1 \mathrm{ml}$ volume using a gentle stream of nitrogen gas in a TurboVap and transferred to a $4 \mathrm{ml}$ vial. The solid shale sample was crushed to a fine powder in a solvent-cleaned mortar and pestle. The powdered shale was transferred to a precombusted glass beaker, covered with dichloromethane and sonicated for $15 \mathrm{~min}$. The dichloromethane extract was decanted into a clean vial and the sonication extraction repeated two additional times. The combined dichloromethane sonication extracts were evaporated to $\sim 1 \mathrm{ml}$ volume using a gentle stream of nitrogen gas in a TurboVap and transferred to a $4 \mathrm{ml}$ vial. Internal standards ( $5 \alpha$-androstane and 1,1'-binapthyl) were added to both the liquid and solid extracts, and the dichloromethane replaced with hexane via three evaporation/hexane addition steps. At no time was the extract allowed to go completely dry.

\subsection{Column chromatography}

Samples were separated into aliphatic, aromatic, and polar fractions with silica-gel column chromatography using a procedure modified from Bastow et al. (2007). Silica gel was prepared by extracting with 9:1 dichloromethane:hexane at $100{ }^{\circ} \mathrm{C}$ in an Accelerated Solvent Extractor (Dionex ASE-350) and drying at $125^{\circ} \mathrm{C}$ for at least $12 \mathrm{~h}$. Glass Pasteur pipettes were plugged with glass wool and pre-combusted at $450{ }^{\circ} \mathrm{C}$ for $8 \mathrm{~h}$. Pipette columns were prepared with $0.50 \mathrm{~g}$ of silica gel (dry-pack) and rinsed with $4 \mathrm{ml}$ of hexane. The sample was loaded onto the column in $200 \mu \mathrm{l}$ of hexane and eluted with $1.0 \mathrm{ml}$ of hexane plus $0.5 \mathrm{ml}$ of $7: 3$ hexane:dichloromethane (F1, aliphatic), $1.0 \mathrm{ml}$ of $7: 3$ hexane:dichloromethane plus $0.5 \mathrm{ml}$ of dichloromethane (F2, aromatic) and $1.0 \mathrm{ml}$ dichloromethane plus $2.5 \mathrm{ml}$ of methanol (F3, polar). (The sequential solvents for each fraction account for the holdup volume of the column.) The aromatic fraction was evaporated under a gentle stream of $\mathrm{N}_{2}$ gas to $\sim 100 \mu \mathrm{l}$ of dichloromethane for gaschromatography.

\subsection{Sample quantification}

Samples were analyzed using a gas chromatograph mass spectrometer (GC-MS, Agilent 7890A GC and 5975C MSD) equipped with a multi-mode inlet (MMI, deactivated single-taper liner without wool packing) and DB-5 ms column ( $30 \mathrm{~m}$ length, $250 \mu \mathrm{m}$ i.d., $0.25 \mu \mathrm{m}$ phase thickness) at $1.0 \mathrm{ml} / \mathrm{min}$ helium flow. One microliter of sample in dichloromethane was injected splitless into the MMI and the MMI temperature held at $60{ }^{\circ} \mathrm{C}$ for $0.1 \mathrm{~min}$ and then ramped to $320^{\circ} \mathrm{C}$ at $15^{\circ} \mathrm{C} / \mathrm{s}$ and held for the remaining acquisition time. The oven temperature was held at $60^{\circ} \mathrm{C}$ for $1.5 \mathrm{~min}$, ramped to $150{ }^{\circ} \mathrm{C}$ at $15^{\circ} \mathrm{C} / \mathrm{min}$ and then to $320^{\circ} \mathrm{C}$ at $4{ }^{\circ} \mathrm{C} / \mathrm{min}$ where it was held for $20 \mathrm{~min}$. The MSD ion source was held at $300^{\circ} \mathrm{C}$ with an electron energy of $70 \mathrm{eV}$ and a quadrapole temperature of $150{ }^{\circ} \mathrm{C}$. The MSD was operated in a hybrid scan and single ion monitoring (SIM) mode, scanning from 50-550 dalton and SIM monitoring of $178.1,192.1$ and 254.1 with a $50 \mathrm{~ms}$ dwell time. The cycle time for the hybrid scan/SIM acquisition was 2.7 scans/s. Peaks were integrated with the Chemstation software, using SIM peak areas for the phenanthrenes and internal standard, and scan peak areas for other compounds such as naphthalene and methylnaphthalenes.

For each laboratory-heated sample, concurrent GC-MS analysis of a standard with 9-, 1-, 3- and 2-methylphenthrenes, phenanthrene and the 1,1'-binaphthyl internal 
standard was used to calibrate the relative response ratio of the five target compounds to the internal standard. The standard solution was prepared with authentic compounds purchased from Chiron AS (Trondheim, Norway). Response ratios from phenanthrene and methylphenanthrenes were used for naphthalene and methylnaphthalenes, respectively.

\subsubsection{Abundance of methylphenanthrenes}

The ratio of stable $\beta$-MP isomers to unstable $\alpha$-MP isomers is used to calculate the Methylphenanthrene Index MPI-1. This ratio measures the amount of methylphenanthrene's refractory isomers 2- and 3-methylphenanthrene relative to the less stable isomers 9- and 1-methylphenanthrene and increases with thermal maturity (Radke et al., 1982b; Szczerba and Rospondek, 2010). Calculations are on a weight basis from concentrations determined by GC-MSD:

MPI-1 $=\frac{1.5(2 \mathrm{MP}+3 \mathrm{MP})}{\mathrm{P}+1 \mathrm{MP}+9 \mathrm{MP}}$

\subsection{Determination of kinetic parameters}

The MPI-1 ratio reflects multiple processes that include formation of new methylphenanthrenes from other compounds, interconversion between methylphenanthrenes and destruction of methylphenanthrenes. Although we can see that these processes are taking place within our experiments, the kinetics do not exist for each of these individual reactions, and our experiments do not allow for determination of each of these processes. However, what is important for this study is the net effect of these various reactions and how this is preserved in fault zones. The net effect can be measured from our experiments by treating the MPI-1 as a reactant whose "concentration" follows first-order reaction kinetics. As we show below, this treatment provides an excellent fit to our experimental data. Work underway in our lab will test the accuracy of extrapolating these kinetic parameters to timescales shorter than those encompassed in our study.

The change in the MPI-1 ratio was treated as a firstorder reaction and the pre-exponential factor and activation energy determined by regression. MPI-1 was first transformed into a measure of reaction extent $(F)$ assuming the MPI-1 ratio starts at zero $\left(\mathrm{MPI}_{\min }\right)$ and proceeds until it reaches $1.6\left(\mathrm{MPI}_{\max }\right)$ :

$F=1-\frac{\mathrm{MPI}_{\text {meas }}-\mathrm{MPI}_{\text {min }}}{\mathrm{MPI}_{\text {max }}-\mathrm{MPI}_{\text {min }}}$

The $\mathrm{MPI}_{\max }$ value derives from observations indicating the MPI-1 ratio maximizes at $\sim 1.6$ and then either remains constant (Szczerba and Rospondek, 2010) or decreases (Radke et al., 1982a) with further heating. The MPI min $_{\text {}}$ value is assumed zero although could have some finite, small value for the first phenanthrenes formed. The MPI $\mathrm{I}_{\min }$ value cancels in the calculation of the rate constants, and so does not influence the final result. Temperatures for the experiments ( $T$, Kelvin) were determined by the time the sample spent within $5 \%$ of the maximum temperature. This likely underestimates the total time because some reaction occurs as the reactor heats up (Fig. 3).

Rate constants $(k)$ for each experiment were calculated from the reaction extent $(F)$ and heating time ( $t$, seconds):

$k=-\frac{\ln \left(\frac{F}{F_{0}}\right)}{t}$

where

$\frac{F}{F_{0}}=\frac{\mathrm{MPI}_{\max }-\mathrm{MPI}_{t}}{\mathrm{MPI}_{\max }-\mathrm{MPI}_{t_{0}}}$

calculated from Eq. (2). The activation energy $\left(E_{a}\right)$ and preexponential constant $(A)$ were determined from the slope and intercept of a least-squares regression to the experimental data:

$\ln (k)=\ln (A)-\frac{E_{a}}{R_{g}} T^{-1}$

where $R_{g}$ is the universal gas constant. Uncertainty in the fitting parameters was determined by a parametric bootstrap method using the regression residuals as the sampling distribution for uncertainty in the $y(\ln k)$ values.

We also determined kinetic parameters with an alternate analysis that uses the full time-temperature history of the experiments. For each experiment we conducted a parameter search for the combinations of $\ln (A)-E_{a}$ values that correctly predict the final MPI-1 value. Each potential $\ln (A)-E_{a}$ pair was used in a forward model with a burial heating step to account for the initial MPI-1 ratio and the experimental time-temperature history to predict the final MPI-1 value and the measured-expected MPI-1 value calculated. Note that the choice of time and temperature for the burial heating step has no effect on this analysis as long as they result in the measured initial MPI-1 ratio. The values of $\ln (A)$ and $E_{a}$ from this analysis were determined by finding the $\ln (A)-E_{a}$ pair that yielded the minimum rootmean squared error of the measured minus expected values for all experiments.

Two experiments (\#4 and \#10) had temperature anomalies during the experiments due to equipment malfunction that indicate the recorded temperatures did not reflect the

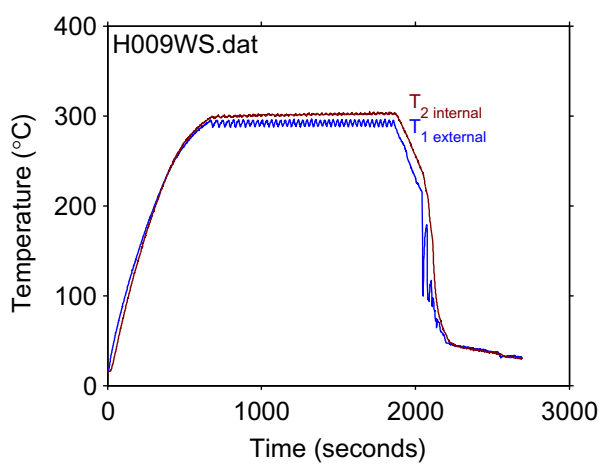

Fig. 3. Example of the time-temperature evolution of an experiment. The external temperature drives the partial-integral differential (PID) controller while the internal temperature is used for the kinetic analyses. 
actual temperature. These experiments are not included in the analysis of kinetic parameters. However, chemical concentrations and maturity indices from these experiments are included in tables and figures.

\section{RESULTS}

The experiments performed here demonstrate that methylphenanthrenes react on the timescale of minutes to hours. In total, 10 heating experiments and one unheated control experiment were conducted at times ranging from 15 to $157 \mathrm{~min}$ and temperatures ranging from 267 to $343{ }^{\circ} \mathrm{C}$ (Table 1). Thermal maturity analyses were conducted on both the rock and the water from each experiment. The change in thermal maturity is evident in the gas chromatograms of heated and unheated samples (Fig. 4), documenting increases in the relative abundance of phenanthrene and 2- and 3-methylphenanthrene, as expected from previous studies.

\subsection{Molecular concentrations and temperature effects on the MPI-1 index}

Fig. 5 shows that the total abundance of phenanthrenes in the rock does not change significantly with increasing thermal maturity, whereas their abundance in the water increases with maturity. The total amount of phenanthrenes (rock plus water) increases with maturity, indicating that new phenanthrenes must be generated from other organic compounds during the experiment. The concentration of phenanthrenes in rock from the unheated (control) experiment was greater than in any of the heated experiments, which suggests heating facilitated expulsion of preexisting bitumen within the rock (Fig. 5). Additionally, some phenanthrenes are dissolved into the water even without heating (Fig. 5).

The MPI-1 value increases strongly with experimental temperature in both the rock and water extracts (Fig. 6). Experimental time is also important, as shown by the increased maturity of the longer experiments (darker colors
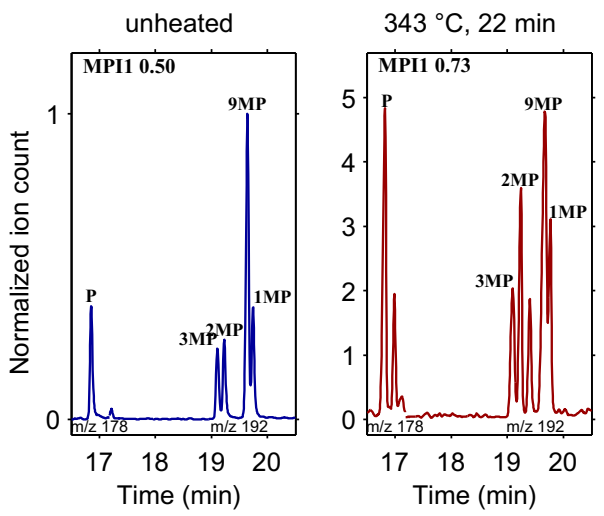

Fig. 4. Gas chromatograms illustrating the initial distribution of methylphenanthrenes in Woodford Shale and the change occurring with the maximum heating experiment (pyrolyzates from experiments 5 and 7). Selected ion abundances for phenanthrene $(\mathrm{m} / \mathrm{z}$ $178)$ and methylphenanthrenes $(\mathrm{m} / \mathrm{z}$ 192) are scaled to the change in fractional abundances between experiments.

in Fig. 6), but maximum temperature has a greater effect across our experiments. Although the rock sample increases in thermal maturity with temperature, the pyrolyzate expelled into the water has a consistently higher maturity and a stronger relationship between maturity and temperature. As discussed below, this likely reflects preferential expulsion of higher maturity phenanthrenes out of the rock into the water, leaving the rock with a lower maturity signature. This process is evident in the lowest temperature experiments where the final MPI-1 value of the rock sample is lower than the unheated sample. At these temperatures, preferential expulsion has a larger effect on the rock MPI1 values than thermal maturation although the MPI-1 of the total system (rock plus pyrolyzate) increases. The thermal maturity of the total phenanthrenes (rock plus pyrolyzate) is similar to the pyrolyzate alone due to the higher concentrations in the water compared to the rock extracts.

It is important to understand the molecular controls on the MPI-1 ratio, such as rates of creation and destruction,

Table 1

Conditions during hydrous pyrolysis experiments.

\begin{tabular}{|c|c|c|c|c|}
\hline Exp. \# & Sample weight (g) & Max. temp. $\left({ }^{\circ} \mathrm{C}\right)$ & Total time (min) & Time at $\max T(\min )^{\mathrm{a}}$ \\
\hline 1 & 6.004 & 307 & 157 & 59.57 \\
\hline 2 & 6.004 & 335 & 60 & 28.17 \\
\hline 3 & 5.998 & 330 & 60 & 28.95 \\
\hline $4^{b}$ & 6.003 & - & 30 & - \\
\hline $5^{\mathrm{c}}$ & 6.001 & - & 0 & - \\
\hline 7 & 6.004 & 343 & 30 & 22.05 \\
\hline 8 & 6.009 & 287 & 60 & 53.78 \\
\hline 9 & 6.005 & 301 & 30 & 24.18 \\
\hline $10^{\mathrm{b}}$ & 6.000 & - & 15 & - \\
\hline 11 & 5.999 & 267 & 30 & 25.43 \\
\hline 12 & 6.006 & 267 & 120 & 115.60 \\
\hline 14 & 5.996 & 307 & 30 & 23.22 \\
\hline 15 & 6.006 & 325 & 30 & 20.87 \\
\hline
\end{tabular}

a Time within $5 \%$ of maximum $T$ (in Kelvin).

${ }^{\mathrm{b}}$ Experiments not used in kinetic analysis.

${ }^{c}$ Unheated control. 


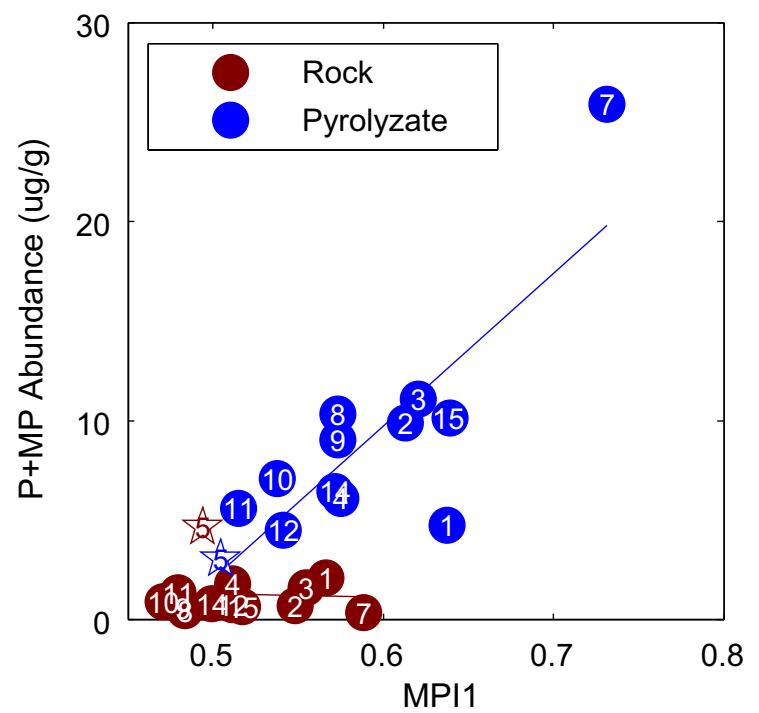

Fig. 5. Absolute abundance of phenanthrene plus methylphenanthrenes in rock extracts and expelled oil (pyrolyzate). Stars denote unheated sample and numbers refer to individual heating experiments in Table 1 .

and the variation between $\alpha$ and $\beta$ isomers. In agreement with previous studies of methylphenanthrenes, 9-MP is found to be the most abundant isomer, and 2-MP is more abundant than 3-MP (Szczerba and Rospondek, 2010) (Fig. 7, Table 2). The fractional abundance of the phenanthrene molecules indicates that increasing MPI-1 ratios are driven by increasing 2- and 3-methylphenanthrenes and decreasing 9-methylphenanthrene in both the rock and water as expected from prior studies. Increasing 1-methylphenanthrene proportions in the rock and increasing phenanthrene proportions in both the rock and water offset some of the MPI-1 increase. The higher MPI-1 value and larger MPI-1 increase in the pyrolyzate compared to the rock is driven by overall higher concentrations of 2- and 3-methylphenanthrene in the pyrolyzate, lower concentrations of 9-methylphenanthrene in the pyrolyzate and the opposing sign of the 1-methylphenanthrene proportions in rock and pyrolyzate as maturity increases.

The increase in MPI-1 with heating is also mirrored by additional maturity indices (Fig. 8). Alternate maturity parameters based on methylphenanthrene molecules such as the methylphenanthrene index-3 (MPI-3) and methylphenanthrene ratio (MPR-1) show a significant, positive relationship with the MPI-1 ratio. This is important because the MPI-1 ratio includes a relatively stable molecule, phenanthrene, in the denominator. Inclusion of phenanthrene in this way may be the cause of reversals in the MPI-1 ratio at very high maturities (Szczerba and Rospondek, 2010). Therefore, the consistency between the MPI-1 ratio and these other parameters indicates that exclusion of phenanthrene does not affect the results and there has not been any reversal of the MPI-1 ratio. An additional maturity parameter, the methylnaphthalene ratio (MNR) also behaves similarly to the MPI-1 ratio. The MNR is based upon the relative abundances of 1- and 2-methylnapthalenes, whose thermal stabilities are different due to differing steric effects. Similar evolution of the MNR indicates that the factors controlling methylphenanthrene evolution are also acting on other PAH compounds in a similar manner. These similar trends provide confidence that the MPI-1 is reflecting overall thermal maturity of the samples.

\subsection{Kinetic analysis}

Rate constants for the MPI-1 value increase with temperature for both water and rock (with the exception of the few experiments at lower temperature discussed above, where the rock MPI-1 is lower than the initial, unheated value). Fig. 9 demonstrates that the reaction constant $(k)$ increases with increasing temperature and is well fit by Eq. (5). Furthermore, the temperature dependence of the rate constant is similar for both rock (Fig. 9A) and the expelled pyrolyzate (Fig. 9B) suggesting they are both dominantly governed by thermal maturation (Table 3 ). We also calculate kinetics for the total system determined by summing the concentration of each molecule in the pyrolyzate and rock extract and then calculating the MPI-1 ratio
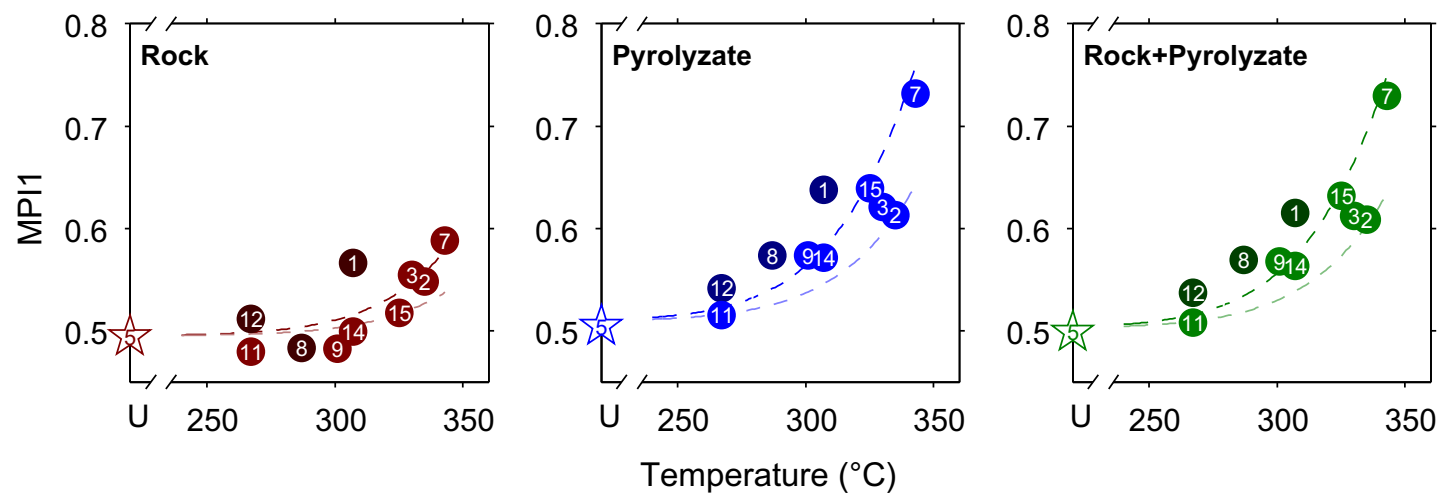

Fig. 6. Measured MPI-1 as a function of temperature in rock extracts, pyrolyzate and combined rock and pyrolyzate. Upper and lower dashed lines are the MPI-1 predicted for 15 and 30 min of heating using the kinetic parameters from this study. Darkly colored symbols indicate longer pyrolysis experiments $(>60 \mathrm{~min}$ ). Numbers refer to individual heating experiments in Table 1. (For interpretation of the references to color in this figure legend, the reader is referred to the web version of this article.) 

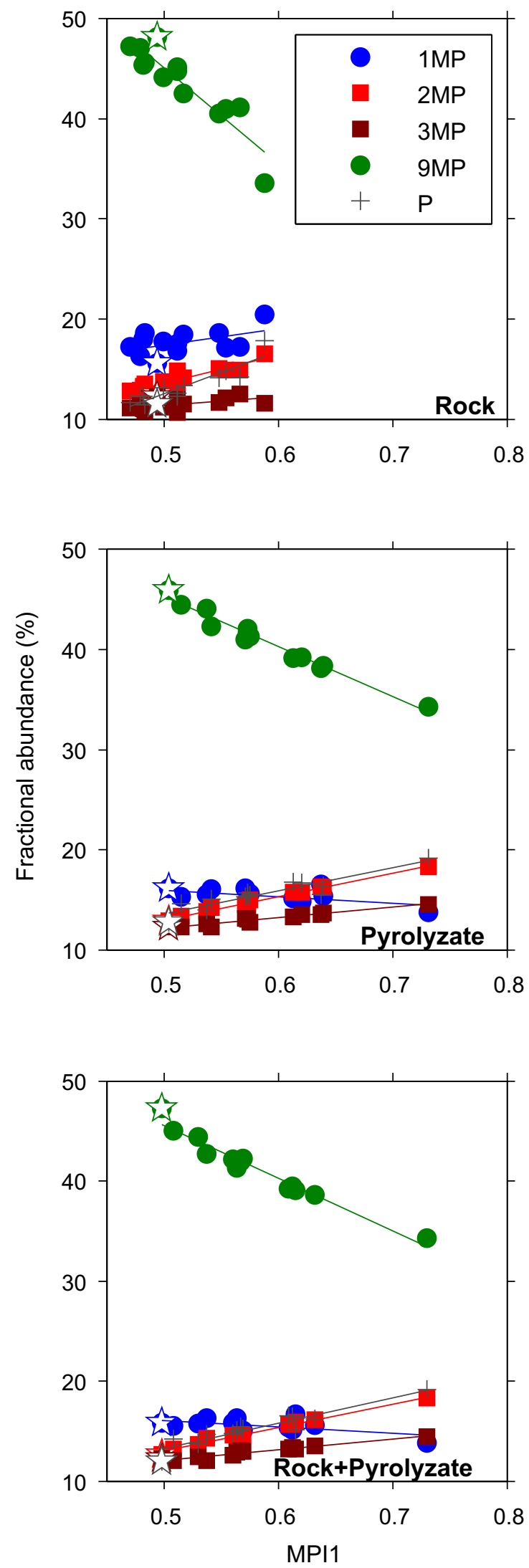

Fig. 7. Relative abundance of phenanthrene isomers in relations to the MPI-1 value for rock extracts, pyrolyzate and combined rock and pyrolyzate. Stars denote unheated sample.
(Fig. 9C). The relationship between reaction extent and time for experiments at the same temperatures is linear in $\ln (F)$ and is thus consistent with pseudo-first order kinetics for the MPI-1 increase (Fig. 10). To our knowledge, this is the first kinetic analysis of methylphenanthrene maturity parameters. The kinetic parameters established for the time-temperature ranges explored in these experiments predict reaction rates slightly below those predicted from vitrinite reflectance kinetics (Sweeney and Burnham, 1990) and correlations with MPI-1 at the longer timescales of burial heating (Radke et al., 1982a) (Fig. 11).

\section{DISCUSSION}

\subsection{MPI-1 increases at temperatures relevant for earthquakes}

The experimental data indicate that methylphenanthrenes and other biomarker indices measurably and systematically increase with time and temperature. The rate at which MPI-1 changes with time at constant temperature is consistent with a first-order kinetic model, as is commonly used for biomarker maturity parameters (Mackenzie and McKenzie, 1983; Alexander et al., 1992, 1997) (Fig. 10). While other models, such as distributed activation energy, might also fit the data, they are not required by the experimental results. The alternative kinetic analysis that uses the full time-temperature history yields activation energies statistically indistinguishable from those determined by assuming a constant reaction temperature. This underscores the greater importance of temperature in determining the reaction rate over the range of heating times in this study, as the constant-temperature analysis ignores the heat-up and cool-down periods of the experiment. The alternative kinetic analysis also reveals that there are relatively strong constraints on the activation energy, weaker constraints on the pre-exponential constant and a strong relationship between the activation energy and pre-exponential constant. These results are expected: the intercept on an Arrhenius diagram is determined by extrapolation far from the centroid of the data and is strongly dependent upon both the slope and its uncertainty.

The experimental data indicate that the MPI-1 value should increase in sedimentary rock-hosted fault zones for temperatures likely reached in earthquakes. This effect is illustrated by Fig. 11, where one second of heating at $\sim 850^{\circ} \mathrm{C}$ will increase MPI-1 close to it maximum value of 1.6. Heating at $600{ }^{\circ} \mathrm{C}$ for one second would still result in a measurable change in the MPI-1 value. These heating levels are substantial but easily achieved in moderate to large sized earthquakes within a fault zone. These heating timescales are shorter than those in our experiments and require extrapolation of kinetic parameters outside of their calibration range. However, heating at lower temperatures and longer times (comparable to our experimental range) is also expected to occur in fault zones as the rapid, localized temperature rise slowly diffuses away from the slip zone. During this diffusive regime, temperatures can remain high for minutes to tens of minutes on and adjacent to the slip zone. This heating regime can also cause measurable 



Fig. 8. Relationship between MPI-1 and other maturity parameters in rock extracts and pyrolyzate. Stars denote unheated sample.
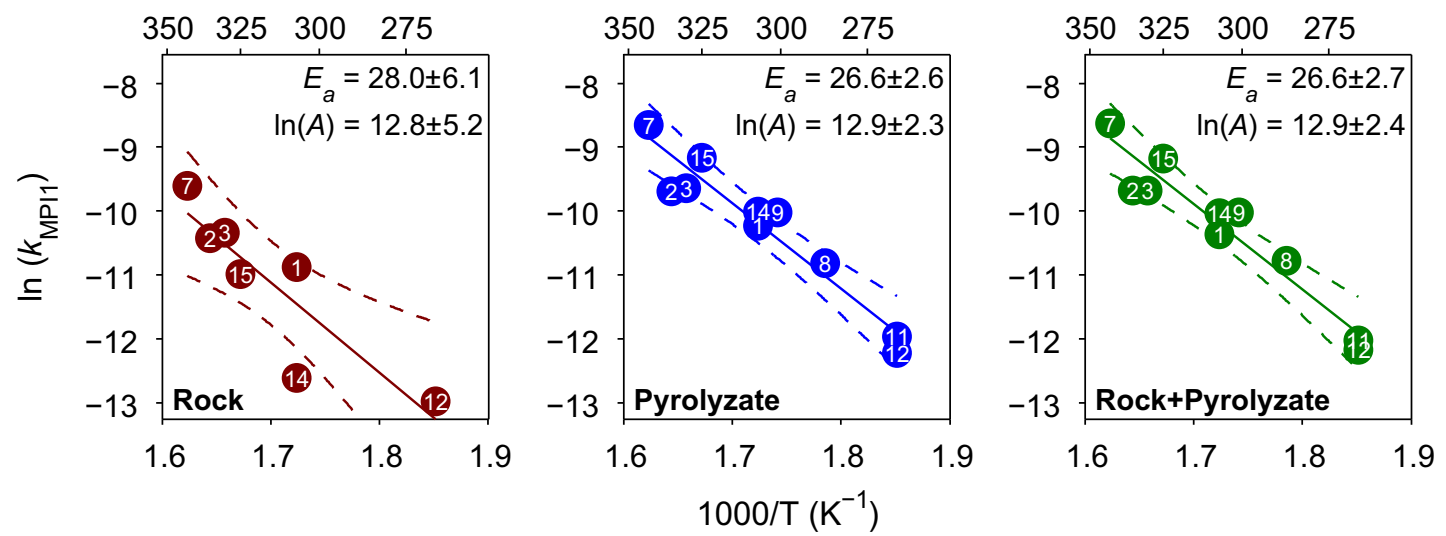

Fig. 9. Arrhenius diagram for fitting kinetic parameters to MPI-1 rate constants in rock extracts, pyrolyzate and combined rock and pyrolyzate (Table 3). Kinetic parameters are determined from the slope and intercept of a linear least-squares fit to the data (solid line) and 3sigma uncertainty in the fit (dashed line). Numbers refer to individual heating experiments in Table 1.

changes in the MPI-1 value that allow detection of a frictional heating event. While we are currently investigating heating at shorter timescales to evaluate kinetic parameters during extremely fast heating events, the present results are directly applicable to samples that experience heating during the diffusive decay of a frictional heating event.

Integrated heating from multiple earthquakes should also leave a measurable increase in the MPI-1 value. The cumulative duration of multiple, short events should produce an MPI-1 increase similar to that from a single event of the same total duration. This sensitivity to integrated heating is a particularly useful feature for applying organic thermal maturity to fault zones, as it can capture the full slip history of a fault, assuming the thermal maturity has not reached a maximum. However, the strong, non-linear dependence of the MPI-1 rate on temperature means that a single, high-temperature event will often dominate the integrated heating signature. Therefore, MPI-1 either reflects the maximum earthquake achieved along the fault, or an integrated signal of the largest events. Future laboratory and modeling work will explore this topic further. The temperature sensitivity range of the MPI-1 measurement complements other higher-temperature approaches for measuring frictional heating, such as melting of silicate minerals to produce pseudotachylyte. This process occurs at temperatures at or above those temperatures where methylphenanthrenes are systematically related to time and temperature (e.g., Spray, 1992) and thus the MPI-1 index provides a critical window into fault processes at temperatures below the melting point.

The kinetics established here suggest that methylphenanthrene maturity can also be used to investigate other short, high-temperature heating events from sources such as shock heating and exposure to igneous activity. Shock heating from hypervelocity impacts can yield extremely high temperatures as demonstrated by theoretical 


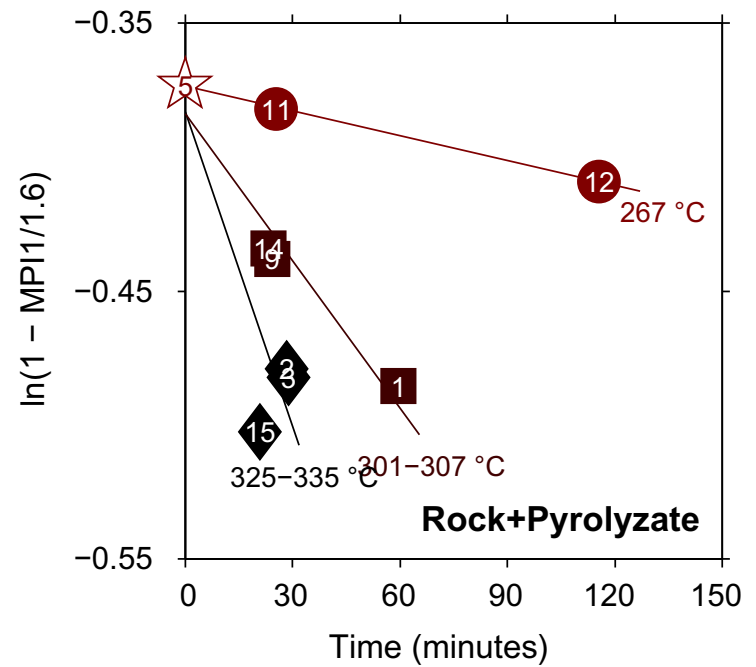

Fig. 10. Relationship between time and fraction remaining $(F=1-$ MPI-1/1.6) for experiments with identical or similar temperatures. The linear decrease of $\ln (F)$ with time is expected for pseudo-first order kinetics. Star indicates unheated sample, lines are least-squares fit to the data.

calculations and the presence of melted rock in some bolide impact structures (French, 1998). Experiments with hypervelocity impactors made from sedimentary rock containing methylphenanthrenes are consistent with these observations and our results. These experiments reached temperatures above $1000{ }^{\circ} \mathrm{C}$ for millisecond timescales and resulted in measurable increases in methylphenanthrene maturity (Bowden et al., 2008; Parnell et al., 2010). This increase was observed without any melt formation, demonstrating the utility of organic thermal maturity for investigating heating at a range of temperatures important in geologic processes.

\subsection{Comparison of experimental kinetics with prior studies}

The kinetics determined from our experiments compare favorably to those determined by burial heating over the range of our experimental timescales and temperatures (Fig. 11). However, the reaction rates extrapolated from burial heating are slightly lower than those predicted from the experiments and a stronger function of temperature. Therefore, the experimental and burial estimates for MPI-1 reaction rates have a crossover point somewhat above the temperatures investigated in the laboratory experiments. Above this crossover temperature, the rates predicted from burial heating become greater than those determined experimentally. Estimates for methylphenanthrene maturation rates from burial heating rely upon an empirical relationship between methylphenanthrene maturity and vitrinite reflectance (Radke et al., 1982a). The relationship is determined from slowly heated sediments in sedimentary basins and extrapolated to shorter heating rates and higher temperatures through kinetic models of vitrinite reflectance. This approach assumes that the relationship between vitrinite reflectance and methylphenanthrene maturity remains the same at all heating rates and temperatures. However, this assumption is unlikely to hold at shorter timescales as has been demonstrated by different relationships between vitrinite reflectance and MPI-1 adjacent to igneous dikes (Raymond and Murchison, 1992; Bishop and Abbott, 1995) where heating occurs over years to centuries. Therefore we take the results of our experiments as more closely applicable to short, high-temperature heating events. Future experiments focused on hydrous pyrolysis at even shorter timescales and higher temperatures will provide an important test for the kinetic parameters determined here.

\subsection{Role of production and expulsion on the MPI-1 ratio}

The experimental results indicate methylphenanthrenes were produced during heating. The total amount of extractable phenanthrenes (phenanthrene plus methylphenanthrenes) increased from 7.6 to $26 \mu \mathrm{g} / \mathrm{g}$, demonstrating substantial formation of new phenanthrene molecules (Fig. 5). Destruction and interconversion may also have occurred but cannot be independently deduced from the data. This finding is consistent with prior studies where absolute biomarker concentrations have been quantified during thermal maturation. These studies demonstrate that differential production and destruction are important processes for most common biomarker thermal maturity indicators (Abbott et al., 1990; Peters et al., 1990; Bishop and

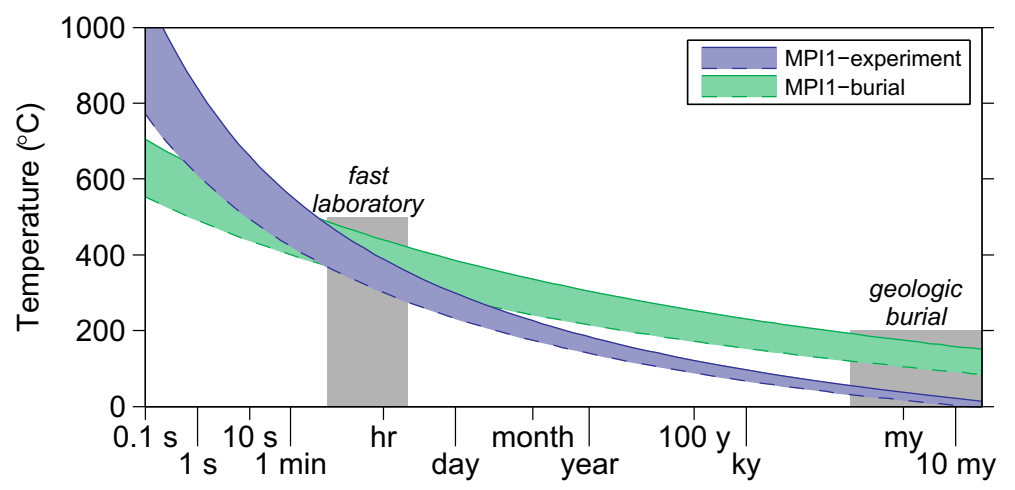

Fig. 11. Time-temperature diagram illustrating the extent of MPI-1 reaction calculated from rapid-heating experiment kinetics and easyR vitrinite kinetics and correlation with MPI-1 at geologic heating rates. The lower and upper bounds of the shaded areas are $10 \%$ and $90 \%$ reaction extent. 
Table 2

Biomarker concentrations (ng/g rock) and thermal maturity ratios.

\begin{tabular}{|c|c|c|c|c|c|c|c|c|c|c|c|c|c|c|c|c|c|c|}
\hline Material & Exp. \# & Max. temp. $\left({ }^{\circ} \mathrm{C}\right)$ & Time at $\max T(\min )$ & $\mathrm{N}^{\mathrm{a}}$ & $2 \mathrm{MN}^{\mathrm{a}}$ & $1 \mathrm{MN}^{\mathrm{a}}$ & $\mathrm{P}_{\mathrm{b}}$ & $3 \mathrm{MP}^{\mathrm{b}}$ & $2 \mathrm{MP}^{\mathrm{b}}$ & $9 \mathrm{MP}^{\mathrm{b}}$ & $1 \mathrm{MP}^{\mathrm{b}}$ & MPsum $^{\mathrm{c}}$ & MPI- $^{\mathrm{c}}$ & MPI- $3^{\mathrm{c}}$ & MPR- $1^{\mathrm{c}}$ & $\mathrm{PAI}^{\mathrm{C}}$ & $\mathrm{MNR}^{\mathrm{c}}$ & $2 \mathrm{MP} / 9 \mathrm{MP}^{\mathrm{c}}$ \\
\hline Rock & 1 & 307 & 59.57 & 58.2 & 138.0 & 144.4 & 298.7 & 261.9 & 313.0 & 862.7 & 360.8 & 2097.1 & 0.566 & 0.470 & 0.868 & 6.02 & 0.956 & 0.363 \\
\hline Rock & 2 & 335 & 28.17 & 23.3 & 40.1 & 40.7 & 94.8 & 78.5 & 101.4 & 272.4 & 125.1 & 672.2 & 0.548 & 0.453 & 0.811 & 6.09 & 0.985 & 0.372 \\
\hline Rock & 3 & 330 & 28.95 & 51.4 & 107.9 & 119.2 & 237.6 & 193.4 & 238.2 & 655.2 & 274.4 & 1598.7 & 0.555 & 0.464 & 0.868 & 5.73 & 0.905 & 0.364 \\
\hline Rock & $4^{\mathrm{d}}$ & & & 39.0 & 88.2 & 99.4 & 225.1 & 214.7 & 241.3 & 809.8 & 301.6 & 1792.5 & 0.512 & 0.410 & 0.800 & 6.96 & 0.887 & 0.298 \\
\hline Rock & $5^{\mathrm{e}}$ & - & - & 61.0 & 100.5 & 138.3 & 533.0 & 569.1 & 580.2 & 2233.0 & 722.2 & 4637.6 & 0.494 & 0.389 & 0.803 & 7.70 & 0.726 & 0.260 \\
\hline Rock & 7 & 343 & 22.05 & 23.0 & 47.2 & 37.6 & 59.7 & 38.9 & 55.4 & 112.4 & 68.4 & 334.9 & 0.588 & 0.522 & 0.810 & 4.61 & 1.256 & 0.493 \\
\hline Rock & 8 & 287 & 53.78 & 6.8 & 12.1 & 14.2 & 51.2 & 48.7 & 60.7 & 205.0 & 83.4 & 449.0 & 0.483 & 0.379 & 0.728 & 7.77 & 0.853 & 0.296 \\
\hline Rock & 9 & 301 & 24.18 & 6.4 & 14.3 & 17.5 & 72.4 & 65.4 & 78.4 & 268.4 & 106.4 & 590.9 & 0.482 & 0.384 & 0.736 & 7.16 & 0.816 & 0.292 \\
\hline Rock & $10^{\mathrm{d}}$ & & & 7.0 & 12.4 & 15.9 & 100.1 & 95.4 & 109.9 & 406.6 & 147.8 & 859.8 & 0.471 & 0.370 & 0.744 & 7.59 & 0.775 & 0.270 \\
\hline Rock & 11 & 267 & 25.43 & 7.7 & 17.7 & 22.0 & 162.1 & 148.5 & 169.3 & 618.1 & 214.3 & 1312.2 & 0.479 & 0.382 & 0.790 & 7.10 & 0.805 & 0.274 \\
\hline Rock & 12 & 267 & 115.60 & 4.8 & 12.3 & 15.6 & 86.1 & 74.7 & 103.9 & 314.6 & 122.9 & 702.2 & 0.512 & 0.408 & 0.846 & 7.16 & 0.790 & 0.330 \\
\hline Rock & 14 & 307 & 23.22 & 10.2 & 24.3 & 30.1 & 99.2 & 84.8 & 103.8 & 333.6 & 133.9 & 755.3 & 0.499 & 0.404 & 0.775 & 6.61 & 0.805 & 0.311 \\
\hline Rock & 15 & 325 & 20.87 & 11.5 & 24.8 & 25.7 & 81.7 & 70.3 & 86.6 & 260.5 & 112.9 & 612.0 & 0.517 & 0.420 & 0.768 & 6.49 & 0.966 & 0.333 \\
\hline Pyrolyzate & 1 & 307 & 59.57 & 154.5 & 403.0 & 379.1 & 733.5 & 639.2 & 769.9 & 1801.4 & 779.5 & 4723.4 & 0.638 & 0.546 & 0.988 & 5.44 & 1.063 & 0.427 \\
\hline Pyrolyzate & 2 & 335 & 28.17 & 434.2 & 1063.7 & 911.8 & 1654.4 & 1313.6 & 1557.8 & 3874.1 & 1495.5 & 9895.4 & 0.613 & 0.535 & 1.042 & 4.98 & 1.167 & 0.402 \\
\hline Pyrolyzate & 3 & 330 & 28.95 & 771.7 & 1720.8 & 1473.3 & 1845.8 & 1494.2 & 1741.2 & 4335.2 & 1636.7 & 11053.1 & 0.621 & 0.542 & 1.064 & 4.99 & 1.168 & 0.402 \\
\hline Pyrolyzate & $4^{\mathrm{d}}$ & & & 242.4 & 589.8 & 521.4 & 934.0 & 774.1 & 905.9 & 2504.8 & 943.3 & 6062.1 & 0.575 & 0.487 & 0.960 & 5.49 & 1.131 & 0.362 \\
\hline Pyrolyzate & $5^{\mathrm{e}}$ & - & - & 37.6 & 55.5 & 80.7 & 385.2 & 371.6 & 391.4 & 1393.6 & 489.0 & 3030.8 & 0.505 & 0.405 & 0.800 & 6.87 & 0.687 & 0.281 \\
\hline Pyrolyzate & 7 & 343 & 22.05 & 3317.0 & 6643.7 & 5412.1 & 4964.0 & 3759.4 & 4741.8 & 8894.2 & 3569.2 & 25928.4 & 0.732 & 0.682 & 1.329 & 4.22 & 1.228 & 0.533 \\
\hline Pyrolyzate & 8 & 287 & 53.78 & 401.6 & 875.9 & 868.6 & 1587.6 & 1345.8 & 1505.4 & 4336.2 & 1534.5 & 10309.5 & 0.573 & 0.486 & 0.981 & 5.49 & 1.008 & 0.347 \\
\hline Pyrolyzate & 9 & 301 & 24.18 & 368.4 & 738.2 & 712.9 & 1410.9 & 1184.1 & 1304.9 & 3757.1 & 1344.8 & 9001.8 & 0.573 & 0.488 & 0.970 & 5.38 & 1.035 & 0.347 \\
\hline Pyrolyzate & $10^{\mathrm{d}}$ & & & 120.9 & 253.5 & 258.4 & 991.3 & 892.5 & 978.7 & 3125.7 & 1102.9 & 7091.1 & 0.538 & 0.443 & 0.887 & 6.15 & 0.981 & 0.313 \\
\hline Pyrolyzate & 11 & 267 & 25.43 & 127.6 & 275.8 & 276.2 & 816.8 & 683.7 & 744.1 & 2485.1 & 854.8 & 5584.4 & 0.515 & 0.427 & 0.870 & 5.84 & 0.999 & 0.299 \\
\hline Pyrolyzate & 12 & 267 & 115.60 & 124.0 & 279.1 & 270.9 & 672.0 & 549.4 & 634.2 & 1890.5 & 717.8 & 4463.9 & 0.541 & 0.454 & 0.883 & 5.64 & 1.030 & 0.335 \\
\hline Pyrolyzate & 14 & 307 & 23.22 & 151.0 & 377.3 & 355.5 & 980.5 & 839.8 & 928.2 & 2628.1 & 1031.9 & 6408.4 & 0.572 & 0.483 & 0.900 & 5.54 & 1.061 & 0.353 \\
\hline Pyrolyzate & 15 & 325 & 20.87 & 621.7 & 1401.4 & 1270.5 & 1655.3 & 1381.7 & 1640.7 & 3877.1 & 1557.0 & 10111.7 & 0.639 & 0.556 & 1.054 & 5.11 & 1.103 & 0.423 \\
\hline Sum & 1 & 307 & 59.57 & 212.7 & 541.0 & 523.5 & 1032.1 & 901.1 & 1082.9 & 2664.1 & 1140.3 & 6820.5 & 0.615 & 0.521 & 0.950 & 5.61 & 1.033 & 0.406 \\
\hline Sum & 2 & 335 & 28.17 & 457.5 & 1103.8 & 952.5 & 1749.2 & 1392.1 & 1659.3 & 4146.5 & 1620.6 & 10567.6 & 0.609 & 0.529 & 1.024 & 5.04 & 1.159 & 0.400 \\
\hline Sum & 3 & 330 & 28.95 & 823.2 & 1828.6 & 1592.5 & 2083.5 & 1687.6 & 1979.4 & 4990.3 & 1911.1 & 12651.8 & 0.612 & 0.531 & 1.036 & 5.07 & 1.148 & 0.397 \\
\hline Sum & $4^{\mathrm{d}}$ & & & 281.4 & 678.0 & 620.8 & 1159.1 & 988.8 & 1147.2 & 3314.6 & 1244.9 & 7854.6 & 0.560 & 0.468 & 0.922 & 5.78 & 1.092 & 0.346 \\
\hline Sum & $5^{\mathrm{e}}$ & - & - & 98.6 & 155.9 & 219.0 & 918.3 & 940.7 & 971.6 & 3626.6 & 1211.2 & 7668.4 & 0.498 & 0.395 & 0.802 & 7.35 & 0.712 & 0.268 \\
\hline Sum & 7 & 343 & 22.05 & 3340.0 & 6690.9 & 5449.7 & 5023.6 & 3798.3 & 4797.2 & 9006.6 & 3637.6 & 26263.3 & 0.730 & 0.680 & 1.319 & 4.23 & 1.228 & 0.533 \\
\hline Sum & 8 & 287 & 53.78 & 408.4 & 888.0 & 882.8 & 1638.8 & 1394.5 & 1566.2 & 4541.1 & 1617.9 & 10758.5 & 0.570 & 0.481 & 0.968 & 5.56 & 1.006 & 0.345 \\
\hline Sum & 9 & 301 & 24.18 & 374.8 & 752.5 & 730.5 & 1483.3 & 1249.5 & 1383.3 & 4025.4 & 1451.2 & 9592.7 & 0.567 & 0.481 & 0.953 & 5.47 & 1.030 & 0.344 \\
\hline Sum & $10^{\mathrm{d}}$ & & & 127.9 & 265.9 & 274.3 & 1091.4 & 987.9 & 1088.6 & 3532.4 & 1250.7 & 7951.0 & 0.530 & 0.434 & 0.870 & 6.29 & 0.969 & 0.308 \\
\hline Sum & 11 & 267 & 25.43 & 135.3 & 293.5 & 298.2 & 978.8 & 832.2 & 913.3 & 3103.2 & 1069.1 & 6896.6 & 0.508 & 0.418 & 0.854 & 6.05 & 0.984 & 0.294 \\
\hline Sum & 12 & 267 & 115.60 & 128.8 & 291.4 & 286.4 & 758.1 & 624.1 & 738.1 & 2205.1 & 840.7 & 5166.1 & 0.537 & 0.447 & 0.878 & 5.81 & 1.017 & 0.335 \\
\hline Sum & 14 & 307 & 23.22 & 161.2 & 401.6 & 385.6 & 1079.7 & 924.6 & 1032.0 & 2961.7 & 1165.8 & 7163.8 & 0.564 & 0.474 & 0.885 & 5.64 & 1.041 & 0.348 \\
\hline Sum & 15 & 325 & 20.87 & 633.2 & 1426.1 & 1296.1 & 1737.0 & 1452.0 & 1727.3 & 4137.7 & 1669.8 & 10723.8 & 0.632 & 0.547 & 1.034 & 5.17 & 1.100 & 0.417 \\
\hline
\end{tabular}

$\mathrm{N}$, napthalene; $2 \mathrm{MN}$, 2-methylnapthalene; $1 \mathrm{MN}, 1$-methylnapthalene.

${ }^{b} \mathrm{P}$, phenanthrene; 3-MP, 3-methylphenanthrene; 2-MP, 2-methylphenanthrene; 9-MP, 9-methylphenanthrene; 1-MP, 1-methylphenanthrene.

${ }^{c} \mathrm{MPsum}=1 \mathrm{MP}+2 \mathrm{MP}+3 \mathrm{MP}+9 \mathrm{MP}+\mathrm{P}$

$\mathrm{MPI}-1=1.5 *(2 \mathrm{MP}+3 \mathrm{MP}) /(\mathrm{P}+9 \mathrm{MP}+1 \mathrm{MP})$

$\mathrm{MPI}-3=(2 \mathrm{MP}+3 \mathrm{MP}) /(9 \mathrm{MP}+1 \mathrm{MP}) ;$

$\mathrm{MPR}-1=2 \mathrm{MP} / 1 \mathrm{MP}$

$\mathrm{PAI}-1=(1 \mathrm{MP}+2 \mathrm{MP}+3 \mathrm{MP}+9 \mathrm{MP}) / \mathrm{P} ; \mathrm{MNR}=2 \mathrm{MN} / 1 \mathrm{MN} ; 2 \mathrm{MP} / 9 \mathrm{MP}=2 \mathrm{MP} / 9 \mathrm{MP}$

${ }^{\mathrm{d}}$ Experiments not used in kinetic analysis.

${ }^{\mathrm{e}}$ Unheated control. 
Table 3

MPI-1 rate constants and kinetic parameters.

\begin{tabular}{|c|c|c|c|c|c|c|c|c|c|c|c|}
\hline \multirow[t]{2}{*}{ Exp. \# } & \multirow{2}{*}{$\begin{array}{l}\text { Max. } \\
\text { temp. } \\
\left({ }^{\circ} \mathrm{C}\right)\end{array}$} & \multirow{2}{*}{$\begin{array}{l}\text { Time at } \\
\max T \\
(\min )^{\mathrm{a}}\end{array}$} & \multicolumn{3}{|l|}{ Rock } & \multicolumn{3}{|c|}{ Pyrolyzate } & \multicolumn{3}{|l|}{ Sum } \\
\hline & & & MPI-1 & $\mathrm{F}^{\mathrm{b}}$ MPI-1 & $\mathrm{k}^{\mathrm{c}}$ MPI-1 & MPI-1 & $\mathrm{F}^{\mathrm{b}}$ MPI-1 & $\overline{\mathrm{k}^{\mathrm{c}} \text { MPI-1 }}$ & MPI-1 & $\mathrm{F}^{\mathrm{b}}$ MPI-1 & $\overline{\mathrm{k}^{\mathrm{c}} \text { MPI-1 }}$ \\
\hline 1 & 307 & 59.5667 & 0.638 & 0.601 & $3.62 \mathrm{E}-05$ & 0.566 & 0.646 & $1.89 \mathrm{E}-05$ & 0.615 & 0.615 & $3.14 \mathrm{E}-05$ \\
\hline 2 & 335 & 28.1667 & 0.613 & 0.617 & $6.17 \mathrm{E}-05$ & 0.548 & 0.657 & $2.97 \mathrm{E}-05$ & 0.609 & 0.619 & $6.26 \mathrm{E}-05$ \\
\hline 3 & 330 & 28.95 & 0.621 & 0.612 & $6.45 \mathrm{E}-05$ & 0.555 & 0.653 & $3.24 \mathrm{E}-05$ & 0.612 & 0.617 & $6.28 \mathrm{E}-05$ \\
\hline $4^{\mathrm{d}}$ & & & 0.575 & 0.641 & & 0.512 & 0.680 & & 0.560 & 0.650 & \\
\hline $5^{\mathrm{e}}$ & - & - & 0.505 & 0.685 & & 0.494 & 0.691 & & 0.498 & 0.689 & \\
\hline 7 & 343 & 22.05 & 0.588 & 0.632 & $6.72 \mathrm{E}-05$ & 0.732 & 0.543 & $1.76 \mathrm{E}-04$ & 0.730 & 0.544 & $1.78 \mathrm{E}-04$ \\
\hline 8 & 287 & 53.7833 & 0.483 & 0.698 & $-3.06 \mathrm{E}-06$ & 0.573 & 0.642 & $2.01 \mathrm{E}-05$ & 0.570 & 0.644 & $2.07 \mathrm{E}-05$ \\
\hline 9 & 301 & 24.1833 & 0.482 & 0.698 & $-7.31 \mathrm{E}-06$ & 0.573 & 0.642 & $4.46 \mathrm{E}-05$ & 0.567 & 0.645 & $4.46 \mathrm{E}-05$ \\
\hline $10^{\mathrm{d}}$ & & & 0.471 & 0.706 & & 0.538 & 0.664 & & 0.530 & 0.669 & \\
\hline 11 & 267 & 25.4333 & 0.479 & 0.700 & $-8.79 \mathrm{E}-06$ & 0.515 & 0.678 & $6.36 \mathrm{E}-06$ & 0.508 & 0.682 & $5.95 \mathrm{E}-06$ \\
\hline 12 & 267 & 115.6 & 0.512 & 0.680 & $2.31 \mathrm{E}-06$ & 0.541 & 0.662 & $4.90 \mathrm{E}-06$ & 0.537 & 0.664 & $5.18 \mathrm{E}-06$ \\
\hline 14 & 307 & 23.2167 & 0.499 & 0.688 & $3.34 \mathrm{E}-06$ & 0.572 & 0.643 & $4.52 \mathrm{E}-05$ & 0.564 & 0.648 & $4.39 \mathrm{E}-05$ \\
\hline 15 & 325 & 20.8667 & 0.517 & & $1.69 \mathrm{E}-05$ & 0.639 & 0.600 & $1.05 \mathrm{E}-04$ & 0.632 & 0.605 & $1.03 \mathrm{E}-04$ \\
\hline \multicolumn{4}{|c|}{ Activation energy, $E_{a}$} & \multicolumn{2}{|c|}{$28.02 \pm 6.04^{\mathrm{f}}$} & & \multicolumn{2}{|c|}{$26.62 \pm 2.66^{\mathrm{f}}$} & & \multicolumn{2}{|l|}{$26.58 \pm 2.65^{\mathrm{f}}$} \\
\hline \multicolumn{4}{|c|}{ Pre-exponential constant, $\ln (A)$} & $12.85 \pm 5.17$ & & & \multicolumn{2}{|c|}{$12.90 \pm 2.32^{\mathrm{f}}$} & \multicolumn{3}{|c|}{$12.85 \pm 2.32_{\mathrm{f}}$} \\
\hline
\end{tabular}

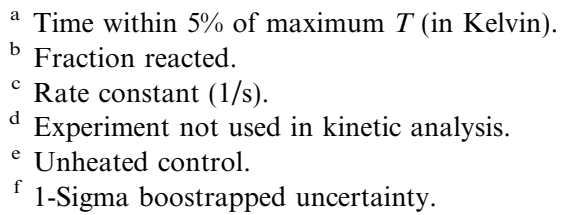

Abbott, 1995). These processes do not negate the validity of biomarker maturity parameters; rather they shift the emphasis of thermal stress towards a mixture of interconversion, production and destruction reactions. Production reactions depend upon both the starting material and stability of the products while interconversion and destruction reactions primarily depend upon molecular stability. Thus, all processes are sensitive to the thermodynamic properties of molecules that form the basis of biomarker thermal maturity parameters.

The experimental results also demonstrate expulsion of methylphenanthrenes into the liquid pyrolyzate. The amount of methylphenanthrenes retained in the rock samples in the heated experiments remained relatively constant $(0.3-2.1 \mu \mathrm{g} / \mathrm{g})$ compared to the large increase in the pyrolyzate concentrations. This suggests a finite capacity of the rock to hold bitumen, likely governed by the pore volume of the shale itself. Greater thermal stress generated larger volumes of bitumen that were continuously expelled from the rock. Prior experiments on Woodford Shale suggests substantial generation of bitumen from these organic rich rocks ( $>20$ wt. $\%$ organic carbon), consistent with our results (Lewan et al., 1985).

One initially puzzling feature is that the unheated rock sample contained greater amounts of methylphenanthrenes than any of the heated rock samples (Fig. 5). This likely reflects bitumen that was originally within pores in the shale but was exposed on new surfaces created as the rock was crushed in preparation for the experiments. This surface bitumen would be removed into the water at even the lowest heating temperatures, as observed in our experiments, but was at least partially retained on the unheated rock.
The concentrations of phenanthrenes in the total system (rock plus pyrolyzate) support this mechanism. The total amount of methylphenanthrenes is similar between the unheated sample and lowest temperature experiments suggesting repartitioning of phenanthrenes off of the rock surface and into the pyrolyzate.

The experimental results also indicate that differential partitioning of methyl isomers between the solid rock and expelled pyrolyzate occurs. This is evident in the consistently higher MPI-1 ratios in the pyrolyzate at all temperatures (Table 2). The primary cause of this difference is the preferentially retention of 1-methylphenanthrene and 9methylphenanthrene in the rock and preferential expulsion of phenanthrene and 3-methylphenanthrene into the pyrolyzate. 1-Methlphenanthrene is particularly influential as the relative concentration increases in the rock while decreasing in the pyrolyzate. Identification of this effect in samples may be possible by comparing MPI-1 values with an alternative maturity parameter that behaves similarly in the rock and pyrolyzate such as 2-MP/9-MP (Table 2).

\subsubsection{Implication for fault zones}

Thermal maturity in fault zones is often measured long after the heat-generating earthquakes have occurred and any pyrolyzate expelled into pore fluids is most likely absent. Therefore careful consideration of the processes of generation and expulsion of methylphenanthrenes must be made when using the MPI-1 index for fault zones. To start, Fig. 6 demonstrates that earthquakes that generate temperatures below $300{ }^{\circ} \mathrm{C}$ over minutes to hours may in fact expel more mature compounds as pyrolyzate than remain within the fault rocks, therefore leaving the fault zone looking less 
thermally mature than the surrounding rock. Although hotter earthquakes must also expel pyrolyzate, more mature compounds are also left behind in the fault zone. Expulsion of pyrolyzate would only occur in organic-rich rocks and thus should not affect faults hosted in organic-poor sediments. It may be possible to test for differential expulsion of methylphenanthrene isomers by comparing several thermal maturity indices such as MPI-1 vs. 2-MP/9-MP that are affected differently by expulsion.

Despite the effects from expulsion, the kinetic parameters for the rock and pyrolyzate samples are very similar (Fig. 9), albeit with more scatter to the fit for the rock samples. Fig. 9 implies that time-temperature of a heating event can still be measurable from just the rock sample. Although this is an avenue that requires further study, the Woodford Shale may be an end-member case of this, as it is a very organic-rich rock and significant quantities of new phenanthrenes can be created during heating. In rocks with a leaner organic content, the expulsion process may be much less significant, as the total volume of new molecules would be smaller.

\section{CONCLUSIONS}

Molecular organic thermal maturity is increasingly used to study thermal history during short heating events such as earthquakes. However, the kinetic parameters necessary to recover time-temperature histories from organic thermal maturation have not been determined for fast, hightemperature heating. We determined kinetic parameters for thermal alteration of methylphenanthrene molecules at minute to hour timescales. Our hydrous pyrolysis experiments on Woodford Shale demonstrate that MPI-1 systematically increases with time and temperature, consistent with a first-order kinetic model and Arrhenius temperature relationship. Significant production of new phenanthrene isomers and expulsion of a liquid pyrolyzate also occurred, consistent with observations from other biomarker maturity systems and experiments on the Woodford Shale. Differential expulsion of methylphenanthrene isomers affected the apparent maturity of the rock at lower temperatures and may need to be considered for organicrich fault rocks. If a similar process occurs in petroleum systems it could also influence source rock maturity inferred from expelled liquids. Our results demonstrate that the overall MPI-1 reaction extent in both the rock and pyrolyzate is a useful measure of thermal maturity and reflects temperature history during rapid heating.

\section{ACKNOWLEDGEMENTS}

Funding for this project was provided by the United States National Science Foundation (EAGER Grant EAR-1219488 and REU supplement), the Columbia Earth Institute intern program, and the Lamont-Doherty Earth Observatory summer intern program. We would like to thank Ted Koczynski for help in the design of the heating apparatus, as well as Geoff Abers and Katie Keranen for collecting Woodford Shale samples. Helpful reviews from Patrick Fulton, Arndt Schimmelmann and one anonymous reviewer are gratefully acknowledged.

\section{REFERENCES}

Abbott G. D., Wang G. Y., Eglinton T. I., Home A. K. and Petch G. S. (1990) The kinetics of sterane biological marker release and degradation processes during the hydrous pyrolysis of vitrinite kerogen. Geochim. Cosmochim. Acta 54, 2451-2461. http://dx.doi.org/10.1016/0016-7037(90)90232-A.

Alexander R., Kralert P. G. and Kagi R. I. (1992) Kinetics and mechanism of the thermal decomposition of esters in sediments. Org. Geochem. 19, 133-140. http://dx.doi.org/10.1016/01466380(92)90032-S.

Alexander R., Kralert P. G., Sosrowidjojo I. B. and Kagi R. I. (1997) Kinetics and mechanism of the thermal elimination of alkenes from secondary stanyl and triterpenyl esters: implications for sedimentary processes. Org. Geochem. 26, 391-398. http://dx.doi.org/10.1016/S0146-6380(97)00006-5.

Armstroff A., Wilkes H., Schwarzbauer J., Littke R. and Horsfield B. (2006) Aromatic hydrocarbon biomarkers in terrestrial organic matter of Devonian to Permian age. Palaeogeogr. Palaeoclimatol. Palaeoecol. 240, 253-274. http://dx.doi.org/ 10.1016/j.palaeo.2006.03.052.

Bastow T. P., van Aarssen B. G. K. and Lang D. (2007) Rapid small-scale separation of saturate, aromatic and polar components in petroleum. Org. Geochem. 38, 1235. http://dx.doi.org/ 10.1016/j.orggeochem.2007.03.004.

Bishop A. N. and Abbott G. D. (1995) Vitrinite reflectance and molecular geochemistry of Jurassic sediments: the influence of heating by Tertiary dykes (northwest Scotland). Org. Geochem. 22, 165-177. http://dx.doi.org/10.1016/0146-6380(95) 90015-2.

Bowden S. A., Court R. W., Milner D., Baldwin E. C., Lindgren P., Crawford I. A., Parnell J. and Burchell M. J. (2008) The thermal alteration by pyrolysis of the organic component of small projectiles of mudrock during capture at hypervelocity. $J$. Anal. Appl. Pyrol. 82, 312-314. http://dx.doi.org/10.1016/ j.jaap.2008.05.002.

Burnham A. K. and Sweeney J. J. (1989) A chemical kinetic model of vitrinite maturation and reflectance. Geochim. Cosmochim. Acta 53, 2649-2657. http://dx.doi.org/10.1016/00167037(89)90136-1.

Cardott B. J. and Lambert M. W. (1985) Thermal maturation by vitrinite reflectance of the Woodford Shale, Anadarko Basin, Oklahoma. Am. Assoc. Pet. Geol. Bull. 69, 1982-1988.

Daly T. K., Buseck P. R., Williams P. and Lewis C. F. (1993) Fullerenes from a Fulgurite. Science 259, 1599-1601. http:// dx.doi.org/10.1126/science.259.5101.1599.

Di Toro G., Han R., Hirose T., De Paola N., Nielsen S., Mizoguchi K., Ferri F., Cocco M. and Shimamoto T. (2011) Fault lubrication during earthquakes. Nature 471, 494-498. http:// dx.doi.org/10.1038/nature09838.

Farrimond P., Bevan J. C. and Bishop A. N. (1999) Tricyclic terpane maturity parameters: response to heating by an igneous intrusion. Org. Geochem. 30, 1011-1019. http://dx.doi.org/ 10.1016/S0146-6380(99)00091-1.

French B. M. (1998) Traces of Catastrophe: A Handbook of ShockMetamorphic Effects in Terrestrial Meteorite Impact Structures. Lunar and Planetary Institute, Houston, TX.

Fulton P. M. and Harris R. N. (2012) Thermal considerations in inferring frictional heating from vitrinite reflectance and implications for shallow coseismic slip within the Nankai Subduction Zone. Earth Planet. Sci. Lett. 335(336), 206-215. http:// dx.doi.org/10.1016/j.epsl.2012.04.012.

Kirkpatrick J. D. and Rowe C. D. (2013) Disappearing ink: how pseudotachylytes are lost from the rock record. J. Struct. Geol. 52, 183-198. http://dx.doi.org/10.1016/j.jsg.2013.03.003. 
Kirkpatrick J. D., Shipton Z. K. and Persano C. (2009) Pseudotachylytes: rarely generated, rarely preserved, or rarely reported? Bull. Seismol. Soc. Am. 99, 382-388. http://dx.doi.org/10.1785/ 0120080114.

Kitamura M., Mukoyoshi H., Fulton P. M. and Hirose T. (2012) Coal maturation by frictional heat during rapid fault slip. Geophys. Res. Lett. 39, L16302. http://dx.doi.org/10.1029/ $2012 \mathrm{~g} 1052316$.

Lewan M. D. (1993) Laboratory simulation of petroleum formation: hydrous pyrolysis. In Organic Geochemistry: Principles and Applications (eds. M. Engel and S. A. Macko). Plenum Press, New York, pp. 419-442, http://dx.doi.org/10.1007/9781-4615-2890-6_18.

Lewan M. D. (1997) Experiments on the role of water in petroleum formation. Geochim. Cosmochim. Acta 61, 3691-3723. http:// dx.doi.org/10.1016/s0016-7037(97)00176-2.

Lewan M. D., Winters J. C. and McDonald J. H. (1979) Generation of oil-like pyrolyzates from organic-rich shales. Science 203, 897-899. http://dx.doi.org/10.1126/ science. 203.4383.897.

Lewan M. D., Spiro B., Illich H., Raiswell R., Mackenzie A. S., Durand B., Manning D. A. C., Comet P. A., Berner R. A. and Leeuw J. W. D. (1985) Evaluation of petroleum generation by hydrous pyrolysis experimentation [and discussion]. Philos. Trans. R. Soc. Lond. A Math. Phys. Eng. Sci. 315, 123-134. http://dx.doi.org/10.2307/37708.

Mackenzie A. S. and McKenzie D. (1983) Isomerization and aromatization of hydrocarbons in sedimentary basins formed by extension. Geol. Mag. 120, 417-470. http://dx.doi.org/ $10.1017 / \mathrm{S} 0016756800027461$.

O’Hara K. (2004) Paleo-stress estimates on ancient seismogenic faults based upon frictional heating of coal. Geophys. Res. Lett. 31, L03601. http://dx.doi.org/10.1029/2003GL018890.

O'Hara K., Mizoguchi K., Shimamoto T. and Hower J. C. (2006) Experimental frictional heating of coal gouge at seismic slip rates: evidence for devolatilization and thermal pressurization of gouge fluids. Tectonophysics 424, 109-118. http://dx.doi.org/ 10.1016/j.tecto.2006.07.007.

Parnell J., Bowden S., Lindgren P., Burchell M., Milner D., Price M., Baldwin E. C. and Crawford I. A. (2010) The preservation of fossil biomarkers during meteorite impact events: experimental evidence from biomarker-rich projectiles and target rocks. Meteorit. Planet. Sci. 45, 1340-1358. http://dx.doi.org/ 10.1111/j.1945-5100.2010.01100.x.

Peters K. E., Moldowan J. M. and Sundararaman P. (1990) Effects of hydrous pyrolysis on biomarker thermal maturity parameters: monterey phosphatic and siliceous members. Org. Geochem. 15, 249-265. http://dx.doi.org/10.1016/0146-6380(90) 90003-i.

Polissar P. J., Savage H. M. and Brodsky E. E. (2011) Extractable organic material in fault zones as a tool to investigate frictional stress. Earth Planet. Sci. Lett. 311, 439-447. http://dx.doi.org/ 10.1016/j.eps1.2011.09.004.

Radke M. (1988) Application of aromatic compounds as maturity indicators in source rocks and crude oils. Mar. Pet. Geol. 5, 224-236. http://dx.doi.org/10.1016/0264-8172(88)90003-7.

Radke M., Welte D. H. and Willsch H. (1982a) Geochemical study on a well in the Western Canada Basin: relation of the aromatic distribution pattern to maturity of organic matter. Geochim.
Cosmochim. Acta 46, 1-10. http://dx.doi.org/10.1016/00167037(82)90285-X.

Radke M., Willsch H., Leythaeuser D. and Teichm, ller M. (1982b) Aromatic components of coal: relation of distribution pattern to rank. Geochim. Cosmochim. Acta 46, 1831-1848. http:// dx.doi.org/10.1016/0016-7037(82)90122-3.

Radke M., Vriend S. P. and Ramanampisoa L. R. (2000) Alkyldibenzofurans in terrestrial rocks: influence of organic facies and maturation. Geochim. Cosmochim. Acta 64, 275-286. http://dx.doi.org/10.1016/S0016-7037(99)00287-2.

Raymond A. C. and Murchison D. G. (1992) Effect of igneous activity on molecular-maturation indices in different types of organic matter. Org. Geochem. 18, 725-735. http://dx.doi.org/ 10.1016/0146-6380(92)90098-I.

Romero A. M. and Philp R. P. (2012) Organic geochemistry of the Woodford Shale, southeastern Oklahoma: how variable can shales be? AAPG Bull. 96, 493-517. http://dx.doi.org/10.1306/ 08101110194.

Sakaguchi A., Chester F., Curewitz D., Fabbri O., Goldsby D., Kimura G., Li C.-F., Masaki Y., Screaton E. J., Tsutsumi A., Ujiie K. and Yamaguchi A. (2011) Seismic slip propagation to the updip end of plate boundary subduction interface faults: vitrinite reflectance geothermometry on Integrated Ocean Drilling Program NanTro SEIZE cores. Geology 39, 395-398. http://dx.doi.org/10.1130/g31642.1.

Savage H. M., Polissar P. J., Sheppard R., Rowe C. D. and Brodsky E. E. (2014) Biomarkers heat up during earthquakes: new evidence of seismic slip in the rock record. Geology 42, 99102. http://dx.doi.org/10.1130/g34901.1.

Schimmelmann A., Mastalerz M., Gao L., Sauer P. E. and Topalov K. (2009) Dike intrusions into bituminous coal, Illinois Basin: $\mathrm{H}, \mathrm{C}, \mathrm{N}, \mathrm{O}$ isotopic responses to rapid and brief heating. Geochim. Cosmochim. Acta 73, 6264-6281. http://dx.doi.org/ 10.1016/j.gca.2009.07.027.

Simoneit B. R. T., Prahl F. G., Leif R. N. and Mao S.-Z. (1994) Alkenones in sediments of the Middle Valley, Leg 139: application as a thermal sensor. In Proceedings of the Ocean Drilling Program, Scientific Results 139 (eds. M. J. Mottl, E. E. Davis, A. T. Fisher and J. F. Slack). Ocean Drilling Program, College Station, TX.

Spray J. G. (1992) A physical basis for the frictional melting of some rock-forming minerals. Tectonophysics 204, 205-221. http://dx.doi.org/10.1016/0040-1951(92)90308-S.

Sweeney J. J. and Burnham A. K. (1990) Evaluation of a simple model of vitrinite reflectance based on chemical kinetics. Am. Assoc. Pet. Geol. Bull. 74, 1559-1570.

Szczerba M. and Rospondek M. J. (2010) Controls on distributions of methylphenanthrenes in sedimentary rock extracts: critical evaluation of existing geochemical data from molecular modelling. Org. Geochem. 41, 1297-1311. http://dx.doi.org/10.1016/ j.orggeochem.2010.09.009.

Wenger L. M., Pottorf R. J., Macleod G., Otten G., Dreyfus S., Justwan H. K. and Wood E. S. (2009) Drill Bit metamorphism: recognition and impact on show evaluation. In SPE Annual Technical Conference and Exhibition. Society of Petroleum Engineers, New Orleans, Louisiana, doi: 10.2118/125218-ms.

Associate editor: Richard Pancost 